\title{
Intercomparison of cloud top altitudes as derived using GOME and ATSR-2 instruments onboard ERS-2
}

\author{
V.V. Rozanov ${ }^{a}$, A.A. Kokhanovsky ${ }^{a, b, *}$, D. Loyola ${ }^{c}$, R. Siddans ${ }^{d}$, B. Latter ${ }^{d}$, \\ A. Stevens ${ }^{\text {d, J.P. Burrows }}{ }^{\text {a }}$ \\ ${ }^{a}$ Institute of Environmental Physics, University of Bremen, D-28334 Bremen, Germany \\ ${ }^{\mathrm{b}}$ Institute of Physics, National Academy of Sciences of Belarus, Minsk, Belarus \\ ${ }^{\mathrm{c}}$ Remote Sensing Technology Institute, German Aerospace Center (DLR), Oberpfaffenhofen, Wessling, Germany \\ d Space Science and Technology Department, Rutherford Appleton Laboratories, Chilton, UK
}

Received 12 September 2005; received in revised form 20 December 2005; accepted 4 February 2006

\begin{abstract}
Cloud top heights as derived using measurements of two instruments (GOME and ATSR-2) onboard the ESA ERS-2 space platform are intercompared. It was found that cloud altitudes obtained using thermal IR measurements of ATSR-2 highly correlate with those obtained from top-of-atmosphere backscattered solar light measurements of GOME in $\mathrm{O}_{2}$ A-band using both the semi-analytical cloud retrieval algorithm SACURA and the neural network cloud retrieval algorithm ROCINN. The average cloud top heights as obtained by these diverse techniques for the whole data set analyzed (931 GOME pixels) differ by $0.6 \mathrm{~km}$ on average, with larger values given by SACURA as applied to GOME data. We found that the standard deviation of SACURA-derived results for cloud top heights from those of ATSR-2 is equal to $1.8 \mathrm{~km}$, while the standard deviation of ROCINN-derived results is equal to $2.2 \mathrm{~km}$. The respective average deviations are $0.6 \mathrm{~km}$ (SACURA) and $-0.5 \mathrm{~km}$ (ROCINN).

(C) 2006 Elsevier Inc. All rights reserved.
\end{abstract}

Keywords: Radiative transfer; Remote sensing; Clouds; Thermal imagery

\section{Introduction}

Knowledge about the vertical distribution of particulate matter (e.g., aerosol, water, and ice clouds) in the terrestrial atmosphere is of importance for many atmospheric research disciplines: cloud physics, chemistry, physics, dynamics, and thermodynamics of the atmosphere. Global information about clouds can be only obtained by using measurements from the instrumentation on satellite platforms. One important parameter is the cloud top altitude.

Rozanov and Kokhanovsky (2004) reviewed modern remote sensing techniques to determine the cloud top height (CTH) from space. The techniques range from very accurate Lidar methods to those based on the stereoscopy. All the methods have their own weaknesses and merits. One important issue is to

\footnotetext{
* Corresponding author. Institute of Environmental Physics, University of Bremen, D-28334 Bremen, Germany.

E-mail address: alexk@iup.physik.uni-bremen (A.A. Kokhanovsky).
}

understand whether data products derived from different instruments can be combined in one database of geophysical cloud parameters. For these differences in retrievals of CTHs using different instruments must be documented. A great progress in this direction has been achieved recently.

In particular, Naud et al. (2002) have studied the difference of cloud top altitudes derived from stereo (Moroney et al., 2002) and thermal IR (Menzel et al., 2002) techniques as applied to data from MISR (Diner et al., 1998) and MODIS (King et al., 1992). In total, 27 cloudy scenes were studied. It was found that the two sets of averaged CTHs were generally within $2 \mathrm{~km}$ of each other, with MODIS CTHs being slightly higher overall. MISR stereo cloud top heights are more sensitive to low-level than to high-level clouds in multiplayer situations. Therefore, MODIS performs better for high clouds (Naud et al., 2002).

The intercomparison of multiple years of MODIS, MISR, and radar cloud top heights was performed by Naud et al. (2005a), who found that MODIS and radar CTHs differ in average by $-1.2 \pm 1.0 \mathrm{~km}$ (Southern Great Plains (SGP) radar, 
USA) and $0.6 \pm 1.3 \mathrm{~km}$ (Chilbolton radar, UK). The correspondent results for MISR are $-0.6 \pm 0.6 \mathrm{~km}$ (SGP, 16 cases) and $-0.2 \pm 0.5 \mathrm{~km}$ (Chilbolton, 14 cases) suggesting that MISR stereo technique is a superior one. However, this is only true for single level clouds and in particular for low-level clouds, where MODIS algorithm uses $11 \mu \mathrm{m}$ thermal IR channel.

Naud et al. (2005b) have compared CTHs as derived using SEVIRI onboard METEOSAT-8 with those obtained using space Lidar system GLAS. SEVIRI results (and also those from MODIS) were found to be generally within $1 \mathrm{~km}$ of Lidar measurement. Naud et al. (in press) compared results of CTHs obtained using ATSR-2 stereo, MOS oxygen A-band, and radar. They found, in particular, that the agreements between the ATSR-2 and 94-GHz radar cloud top height retrievals were within $\pm 1 \mathrm{~km}$ in more than half examined cases. Rozanov et al. (2004) have compared cloud top altitudes as derived from oxygen A-band measurements by GOME (Burrows et al., 1999) and IR measurements by ATSR-2. GOME and ATSR-2 make simultaneous measurements. For a selected number of fully cloudy ground scenes, the difference in the derived CTHs was found to be less than $1 \mathrm{~km}$.

This manuscript extends the investigations described by Rozanov et al. (2004) using a much larger data set (931 GOME ground scenes in total). In addition, the Independent Pixel Approximation (IPA) (described below) in combination with the information on the cloud fraction (Loyola \& Ruppert, 1998) from GOME polarization measurement devices (PMDs) is used to extend the Semi-Analytical CloUd Retrieval Algorithm (SACURA) (Rozanov \& Kokhanovsky, 2004) for the case of broken clouds. GOME retrievals using SACURA for broken clouds are compared with $\mathrm{CTH}$ as retrieved from thermal IR measurements of ATSR-2 and CTH retrieved using ROCINN for GOME data (Loyola, 2004).

Note that the primary goal of GOME is trace gas measurements, not cloud measurements. GOME cannot compete with specialized cloud instruments that provide thermal IR information and smaller ground pixels. However, $\mathrm{CTH}$ as derived from GOME data is of great importance for the accurate determination of ozone vertical columns using this instrument (Spurr et al., 2005).

\section{Instruments and data}

GOME (Burrows et al., 1999) and ATSR-2 (Stricker et al., 1995) are on the same space platform (the ESA Earth Remote Sensing satellite (ERS-2)). The ERS-2 mean altitude is $785 \mathrm{~km}$ and the orbit repeat cycle is 35 days. The ERS-2 is in a Sunsynchronous polar orbit, highly inclined to the equator, giving the satellite visibility of all areas of the Earth as the planet rotates beneath the orbit. The inclination is such that the precession of the orbit, caused by the non-spherical components of the Earth's gravity field, exactly opposes the annual revolution of the Earth around the Sun. Consequently, the orbital plane will always maintain its position relative to the Sun, crossing the equator with the descending node at about 10:30 a.m. local time.
GOME is a grating spectrometer. It collects light arriving from the sun-illuminated atmosphere and yields the spectrum. In order to provide both the spectral coverage (240-790 nm) and a good spectral resolution $(0.2-0.4 \mathrm{~nm})$, a quartz predisperser prism is used to form an intermediate spectrum, which is then split into four different channels. Each of the channels possesses a grating and a 1024 pixel silicon array detector. The ground resolution of GOME is $320 \times 40 \mathrm{~km}^{2}$ or $80 \times 40 \mathrm{~km}^{2}$ depending on the observation mode. Only the enhanced resolution mode of GOME was used in this study. Thus, our results can be also extended to yet another grating spectrometer currently orbiting the planet (the SCanning Imaging Absorption SpectroMeter for Atmospheric CHartographY (SCIAMACHY) on-board the ESA Envisat satellite) and to the GOME-2 spectrometer planed to fly mid 2006 on-board the MetOp satellite. The spatial resolution of SCIAMACHY in the oxygen A-band is $30 \times 60 \mathrm{~km}^{2}$ and spectral resolution is close to that of GOME (Bovensmann et al., 1999), while the spatial resolution of GOME-2 is $80 \times 40 \mathrm{~km}^{2}$ at the normal observation mode.

ATSR-2 has much better spatial resolution $\left(1.1 \times 1.1 \mathrm{~km}^{2}\right)$ and measures reflected or emitted radiation at four bands in the solar part $(0.545-0.565,0.649-0.669,0.855-0.875,1.58-$ $1.64 \mu \mathrm{m})$ and three bands in the thermal infrared part $(3.55-$ $3.93,10.4-1.3,11.5-12.5 \mu \mathrm{m})$ of the spectrum. The ATSR-2 data were averaged to bring them to the scale of a GOME $80 \times 40 \mathrm{~km}^{2}$ pixel.

\section{Retrieval algorithms}

\subsection{IR retrieval algorithm}

ATSR-2 and GOME retrievals of CTHs are based on entirely different physical principles. In particular, cloud brightness temperature as measured by ATSR-2 at 11 and $12 \mu \mathrm{m}$ can be related to the cloud top height. Colder clouds are generally located at higher altitudes in the troposphere. This is the basic idea behind the IR retrieval.

In this study, ATSR-2 cloud top height estimates are derived by a scheme developed at the Rutherford Appleton Laboratory for the specific purpose of characterizing cloud in the GOME field-of-view (Siddans et al., 1999). The IR cloud top height scheme operates as follows:

1. ATSR-2 pixels (at $1.1 \times 1.1 \mathrm{~km}^{2}$ resolution) which lie within a specific GOME field-of-view $\left(80 \times 40 \mathrm{~km}^{2}\right)$ are selected. ATSR-2 "quick-look" data which is subsampled every 4 pixels along and across track from the full product is used (for pragmatic reasons related to data access).

2. Each ATSR-2 pixel is classified into the categories (e.g., thin cloud over sea), making use of visible channel ratios in an NDVI type approach.

3. The minimum altitude at which the local temperature profile (according to UK Met. Office analyses) equals the derived cloud top temperature is then assumed to equal the cloud top height. The corresponding equivalent black body temperature is assumed to equal the cloud top temperature. The black cloud assumption clearly causes problems for thin cirrus. 
Even for thick clouds, there may be a bias associated with scattering. Therefore, the assumption of the black-body in our CTH IR technique may cause additional biases as compared to "true" cloud top height values.

In addition, a second, "stereoscopic" scheme to derive cloud top height was implemented based on the parallax between cloud appearing in the forward and nadir-views of ATSR-2. The wavelength $0.87 \mu \mathrm{m}$ was used in the stereoscopic technique. This approach was developed primarily to provide a better measurement of the altitude of thin cirrus than the IR approach. The latter being limited by the implicit assumption that cloud is optically thick.

This retrieval scheme was applied to all ATSR-2 data for the GOME narrow-swath orbits between April 1998 and April 1999 and the data was made available via the British Atmospheric Data Centre (BADC) (www.badc.rl.ac.uk). It should be noted that results from this scheme will shortly be superceded by those from the NERC GRAPE project (www.atm.ox.ac.uk/group/ grape/), which will also provide cloud and aerosol optical thickness and particle effective radius. The GRAPE scheme is currently being applied to the complete ATSR-2 mission up to January 2001. Results will appear on the BADC website shortly.

\section{2. $\mathrm{O}_{2}$ A-band algorithms: ROCINN and SACURA}

GOME measures the reflected solar light in the UV, visible, and near IR including the oxygen A-band spectral region. The oxygen absorption bands are much more pronounced (in reflected light) for low clouds as compared to high clouds. This is due to the fact that high clouds effectively screen oxygen molecules present in the lower troposphere. This feature is routinely used for the determination of cloud altitudes (Loyola, 2000; Kokhanovsky et al., 2005). In particular, the fit of A-band measured spectra with respect to the modeled ones is performed to derive the cloud top height from GOME data. There are different numerical algorithms for the fitting procedure. In this paper, two independent algorithms are used: ROCINN (Loyola, 2004) and SACURA (Rozanov \& Kokhanovsky, 2004). The SACURA minimization procedure, which based on the asymptotic radiative transfer theory, is described by Rozanov and Kokhanovsky (2004) for fully cloudy pixels in the assumption of a single-layer cloudiness. The ROCINN inversion procedure is based on neural networks and simulated oxygen A-band. It is described by Loyola (2004).

In this work, the use of SACURA is extended to be applicable to broken cloud fields using the independent pixel approximation. This assumes that the measured reflection function of a scene $R_{\text {mes }}$ can be presented as a linear mixture of the reflection fraction of a clear part of the pixel $R_{\mathrm{a}}$ and that of a cloudy part $R_{\mathrm{c}}: R_{\text {mes }}=c_{\mathrm{f}} R_{\mathrm{c}}+\left(1-c_{\mathrm{f}}\right) R_{\mathrm{a}}$. The cloud fraction $c_{\mathrm{f}}$ is obtained using the optical cloud recognition algorithm (OCRA) described by Loyola and Ruppert (1998), briefly summarized in Appendix A. $R_{\mathrm{a}}$ is calculated using a fixed clear atmosphere model described by Kokhanovsky and Rozanov (2004) for different ground albedos (e.g., ocean, land, snow) depending on a geolocation. Then, it follows that the cloud reflection function $R_{\mathrm{c}}=f R_{\text {mes }}+(1-f) R_{\mathrm{a}}$, where $f=1 / c_{\mathrm{f}}$. The derivation of $R_{\mathrm{c}}$ enables the application of SACURA as presented by Rozanov and Kokhanovsky (2004) for the case of completely cloudy ground scenes. We used the following constraints in the SACURA: the cloud geometrical thickness must be in the range $0.8-10 \mathrm{~km}$, the cloud lower boundary must be larger than the surface height $\Lambda$, the cloud top height must be smaller than $18 \mathrm{~km}(10.5 \mathrm{~km}$ for ROCINN) but larger than $\ell=\Lambda+1 \mathrm{~km}$. The retrieved values of $\mathrm{CTH}$ are given with respect to the ground surface height.

The main difference of ROCINN from SACURA is due to the fact that the former substitutes the cloud by a Lambertian reflector. SACURA does not use this assumption and account for the multiple scattering of light in a cloud.

\section{Comparison of cloud top heights obtained using different retrieval techniques and instruments}

Four well-separated GOME orbits were selected for the comparison of the different CTH products (see Fig. 1). The orbits are different with respect to the ground reflectance, the season, the height of clouds, the solar zenith angle, and even year and are considered to give a representative range of conditions. Approximately half of the ground scenes (412 of

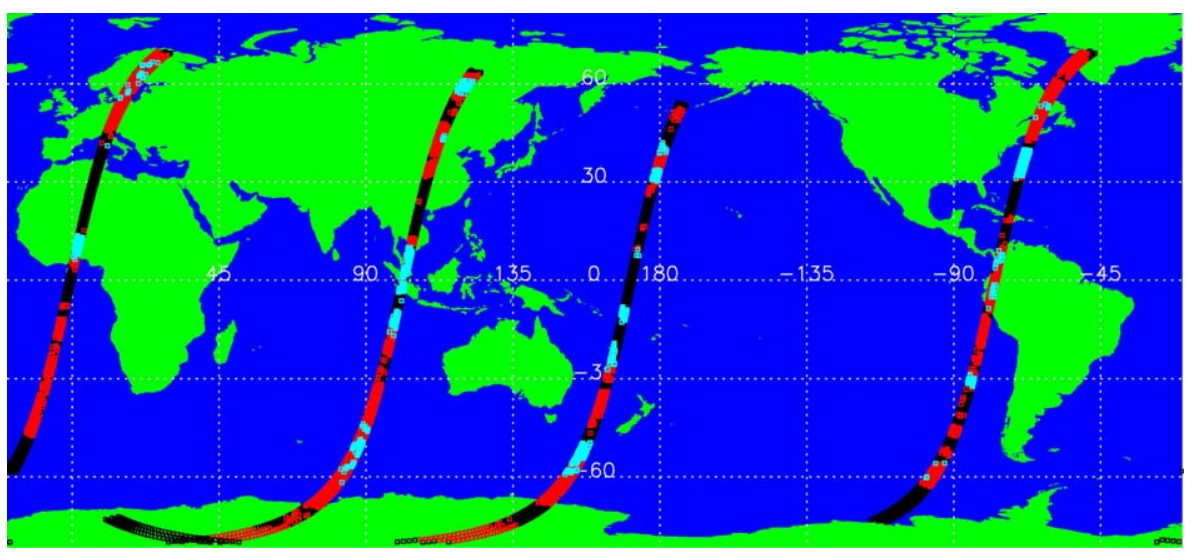

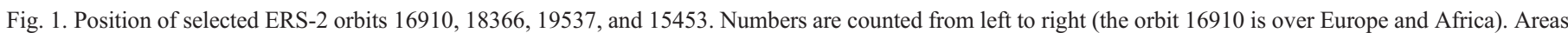

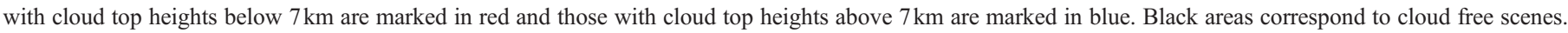


931) were partially covered by clouds and others were completely cloudy. Selected pixels satisfy the following conditions:

$\square$ The reflectance outside oxygen A-band is larger than 0.2. Therefore, the case of thin cirrus clouds is excluded from this study.

$\square$ The cloud optical thickness as retrieved by SACURA is larger than 5 .

$\square$ The solar zenith angle is smaller than $75^{\circ}$.

$\square$ The cloud fraction as retrieved by OCRA (see Appendix A) is larger than 0.2 . We found that the stratification of the data with respect to the cloud fraction does not change main conclusions of this paper.

Clouds with ATSR-2-derived CTHs below $7 \mathrm{~km}$ are presented in red and those with $\mathrm{CTH}$ above $7 \mathrm{~km}$ are plotted in blue in Fig. 1. Black areas in Fig. 1 show cloud free situations.

In Fig. 2, the CTHs derived from the use of SACURA on GOME data and from thermal IR ATSR-2 measurements are plotted and observed to correlate. Partially cloudy scenes are treated in the SACURA GOME retrieval using IPA as described above. The corresponding ATSR-2 data is averaged only for cloudy regions, excluding clear sky pixels. The average deviation $\left\langle B_{\mathrm{s}}\right\rangle=\left\langle H_{\mathrm{s}}\right\rangle-\left\langle H_{\mathrm{IR}}\right\rangle$ is $0.6 \mathrm{~km}$ and the standard deviation $\sigma$ is $1.8 \mathrm{~km}$. Here $\left\langle H_{\mathrm{s}}\right\rangle$ and $\left\langle H_{\mathrm{IR}}\right\rangle$ are average CTHs as derived using SACURA and thermal IR ATSR-2 algorithm, respectively.

The histogram of deviations is shown in Fig. 3. It follows that most of deviations fall within a band of $\pm 1.5 \mathrm{~km}$. The average value of CTH is $6.4 \mathrm{~km}$ for ATSR-2. The correspondent value is $0.5 \mathrm{~km}$ higher for the SACURA GOME retrievals. These data products derived using different instruments and

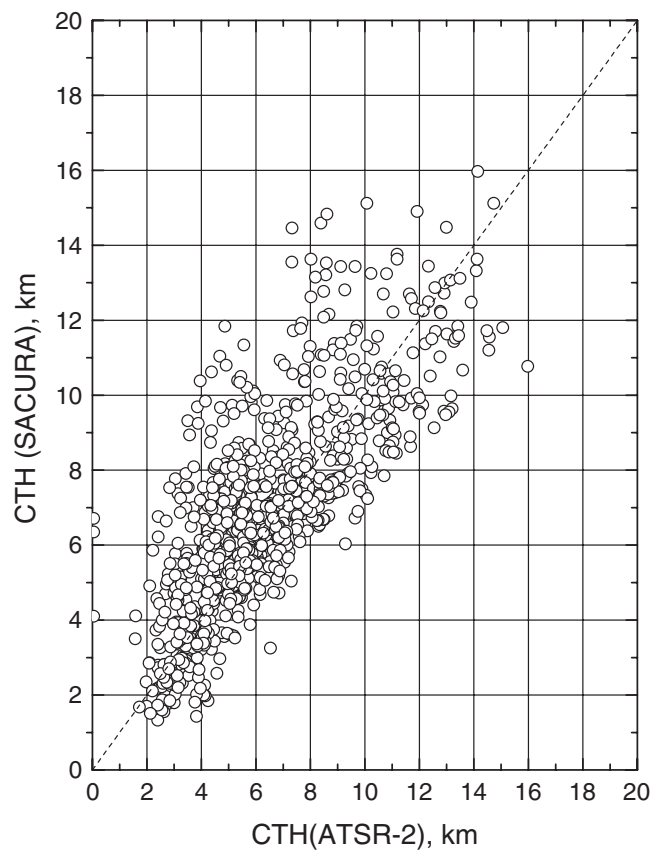

Fig. 2. Correlation plot between CTHs obtained using SACURA and thermal IR measurements of ATSR-2.

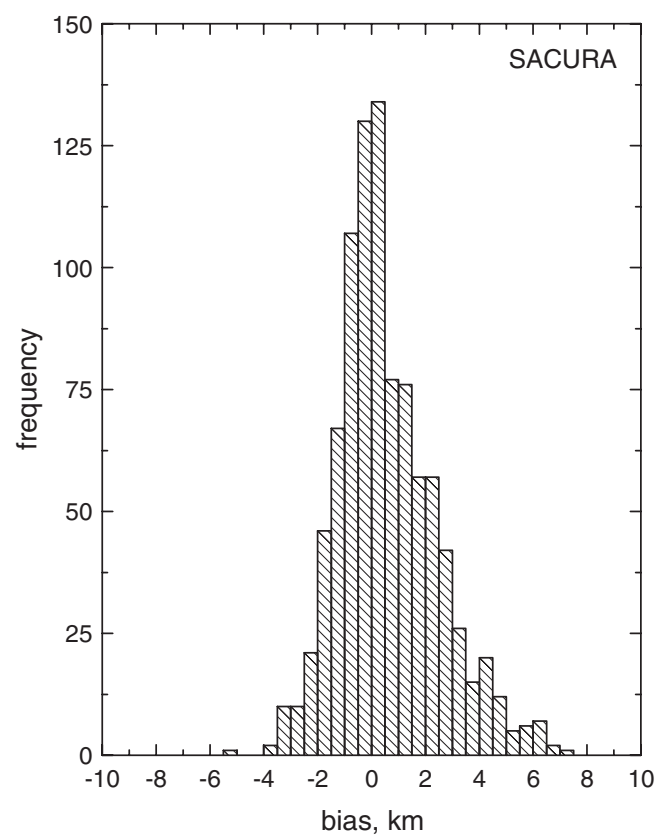

Fig. 3. Histogram of biases of SACURA GOME-derived CTHs as compared to those derived using thermal IR measurements of ATSR-2.

data are similar within error limits. This is encouraging taking into account the difference in the physical background of the retrievals and also the different spatial resolutions of the instruments. Note that the ATSR-2 CTHs $\left(1.1 \times 1.1 \mathrm{~km}^{2}\right.$ resolution) were averaged over the GOME ground scene $\left(80 \times 40 \mathrm{~km}^{2}\right.$ resolution). The difference between the mean $\mathrm{CTH}$ values is probably arises from systematic errors in the assumptions made in the two algorithms. Further work is going on to ascertain where this arises.

The average global cloud top height (for optically thick clouds $\tau>5$ ) is in the range $6-7 \mathrm{~km}$. Taking into account the diversity of cloud situations considered in this work, this is an interesting result by itself.

Assuming that the ATSR-2 cloud top heights are correct then SACURA-derived CTHs from GOME data are shifted somewhat towards larger values of CTH $\left(B_{\mathrm{s}}\right.$ is positive in most of cases, see Fig. 3). To investigate the possible origin of this effect, the bias is plotted as a function of the SACURAretrieved cloud geometrical thickness (CGT) in Fig. 4. SACURA retrieves both cloud top height and cloud geometrical thickness by fitting modeled and measured $\mathrm{O}_{2}$ A-band spectra in the spectral interval 759-772 nm (Kokhanovsky \& Rozanov, 2005). Measurements outside of the gaseous absorption band (at $758 \mathrm{~nm}$ ) are used to determine the cloud optical thickness and the cloud spherical albedo (Kokhanovsky et al., 2005). Large positive values of $B_{\mathrm{s}}$ correspond to large values of the retrieved cloud geometrical thickness. We speculate that cases such as those shown in Fig. 4 at CGT $>5 \mathrm{~km}$ probably correspond to the multi-layered cloud systems. SACURA currently assumes a single-layered cloudiness in the retrieval procedure, but Rozanov et al. (2004) demonstrated that this assumption leads to too large CGTs if in reality two or even more cloud layers are present. Alternatively, ATSR-2 retrievals of CTH could also 


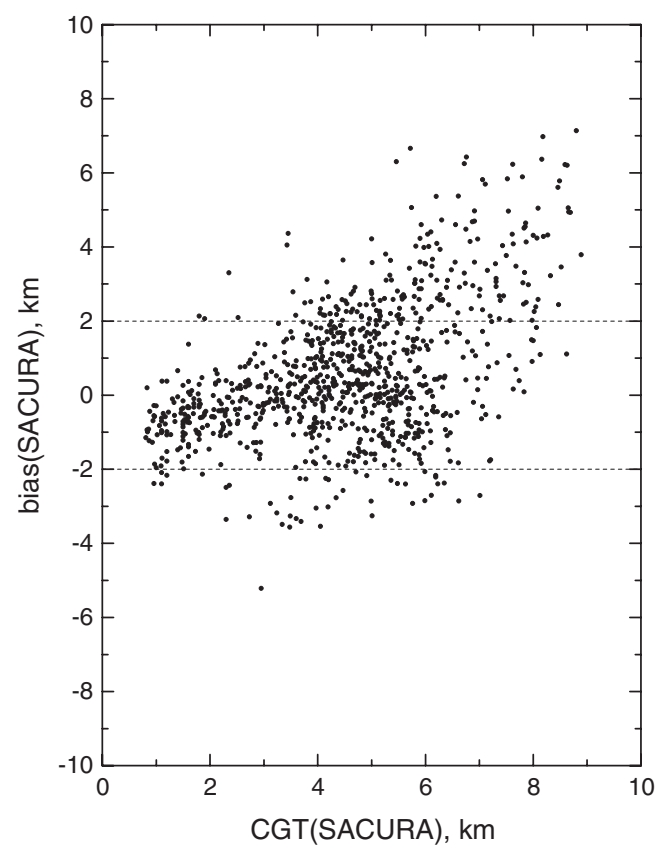

Fig. 4. Dependence of the SACURA bias $B_{\mathrm{s}}$ on the cloud geometrical thickness.

have problems in this case. A key issue is the effective height of the maximum emissivity of the cloud top. Sherwood et al. (2004) found that the cloud top heights obtained using thermal imagery over multiple satellites are underestimated, even for deep convective clouds. Our results for $\left\langle H_{\mathrm{s}}\right\rangle$ and $\left\langle H_{\mathrm{IR}}\right\rangle$ shown in Table 1 confirm this finding. This means that there is a need to understand the problem with the underestimation of CTH by IR retrieval techniques. Most probably, one of reasons behind this effect is the substitution of a cloud by a black body radiator (see above). Radiative transfer calculations in thermal IR with account for multiple scattering of radiation by droplets and crystals must be performed to clarify this situation.

We found that the negative biases larger than $2 \mathrm{~km}$ correspond to large values of ATSR-2-derived CTHs (see

Table 1

Statistical data

\begin{tabular}{lllllr}
\hline Orbit & 15453 & 16910 & 18366 & 19537 & All orbits \\
& 04.04 .1998 & 15.07 .1998 & 25.10 .1998 & 14.01 .1999 & \\
\hline $\begin{array}{l}\text { Number of } \\
\text { GOME pixels }\end{array}$ & 234 & 159 & 325 & 214 & 931 \\
\hline$\left\langle H_{\mathrm{IR}}\right\rangle$ & 6.5 & 6.6 & 5.9 & 6.4 & $6.4 \pm 0.3$ \\
$\left\langle H_{\mathrm{S}}\right\rangle$ & 6.5 & 6.8 & 7.0 & 7.2 & $6.9 \pm 0.3$ \\
$\left\langle H_{\mathrm{R}}\right\rangle$ & 5.2 & 5.0 & 6.2 & 6.8 & $5.8 \pm 0.8$ \\
$\left\langle H_{\text {stereo }}\right\rangle$ & 5.4 & 6.4 & 5.1 & 6.1 & $5.8 \pm 0.6$ \\
$\left\langle B_{\mathrm{s}}\right\rangle$ & -0.1 & 0.1 & 1.1 & 0.8 & $0.6 \pm 0.6$ \\
$\left\langle B_{\mathrm{R}}\right\rangle$ & -1.3 & -1.6 & 0.2 & 0.3 & $-0.5 \pm 1.0$ \\
$\left\langle B_{\text {stereo }}\right\rangle$ & -1.1 & -0.2 & -0.9 & -0.3 & $-0.6 \pm 0.4$ \\
$\sigma_{\mathrm{s}}$ & 1.6 & 1.5 & 2.1 & 2.2 & $1.8 \pm 0.4$ \\
$\sigma_{\mathrm{R}}$ & 2.4 & 2.3 & 2.4 & 1.7 & $2.2 \pm 0.3$ \\
$\sigma_{\text {stereo }}$ & 3.4 & 1.9 & 3.8 & 3.0 & $3.0 \pm 0.8$ \\
\hline Brakets & & & & & \\
\hline
\end{tabular}

Brackets signify average values. $B$ means a bias with respect to IR ATSR-2 retrievals of SACURA (s), ROCINN (R), and stereoscopy (stereo) results. Standard deviations are denoted by $\sigma$. Results are given in kilometers. The geographical position of orbits is shown in Fig. 1.
Fig. 5). This is best interpreted by the fact that GOME nadir measurements are less sensitive to thin Cirrus clouds, which are easily detected by the thermal IR ATSR-2 measurements. This is due to the fact that techniques based on the top-ofatmosphere reflectance measurements in the $\mathrm{O}_{2}$ A-band sample larger atmospheric volumes as compared to IR methods, which give information from tops of single clouds or multi-layered cloud systems.

Interestingly, CTHs retrieved using ATSR-2 stereo techniques are considerably biased with respect to ATSR-2 IR-based retrievals (see Fig. 6). The average CTH from Stereo Technique (ST) is $0.6 \mathrm{~km}$ lower than that derived from the IR method (see Table 1). The standard deviation of ST from IR results is $3.0 \mathrm{~km}$. This is, probably, due to the fact that the stereo technique has troubles in multi-layer situations because it is based on backscattered solar light measurements. Naud et al. (2002) reported similar findings (but with $2 \mathrm{~km}$ biases) for MODIS IR and MISR stereo techniques. Most probably, the differences between MODIS IR and MISR (and also ATSR-2 IR and stereo techniques) cloud top heights can be attributed to different clouds, noting that stereo finds the heights of the cloud surface that provides the maximum spatial contrast, which may be under a thin cirrus layer. Hence, one can expect that stereo gives lower clouds as compared to the IR method based on the cloud top temperature measurements. This is what really observed in our intercomparison study as well.

Our findings are summarized in Table 1, where we also present results for each orbit shown in Fig. 1 separately. The difference of IR ATSR-2 results from those obtained using SACURA GOME data is approximately $0.6 \mathrm{~km}$. This does not differ considerably from the $1 \mathrm{~km}$ bias reported earlier in a similar study (but for a smaller data set) by Rozanov et al. (2004).

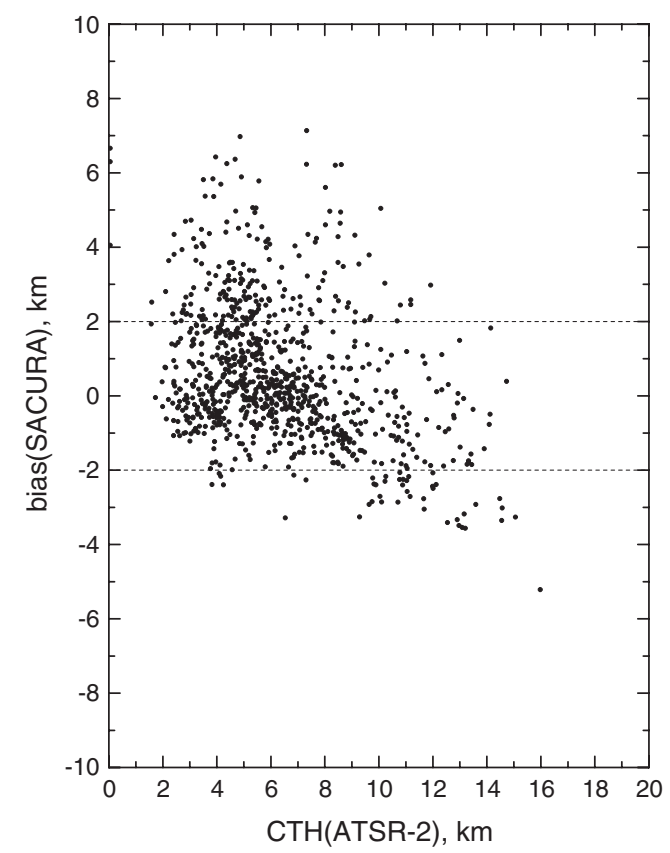

Fig. 5. The same as in Fig. 4 but as the function of the CTH derived using thermal IR ATSR-2 measurements. 


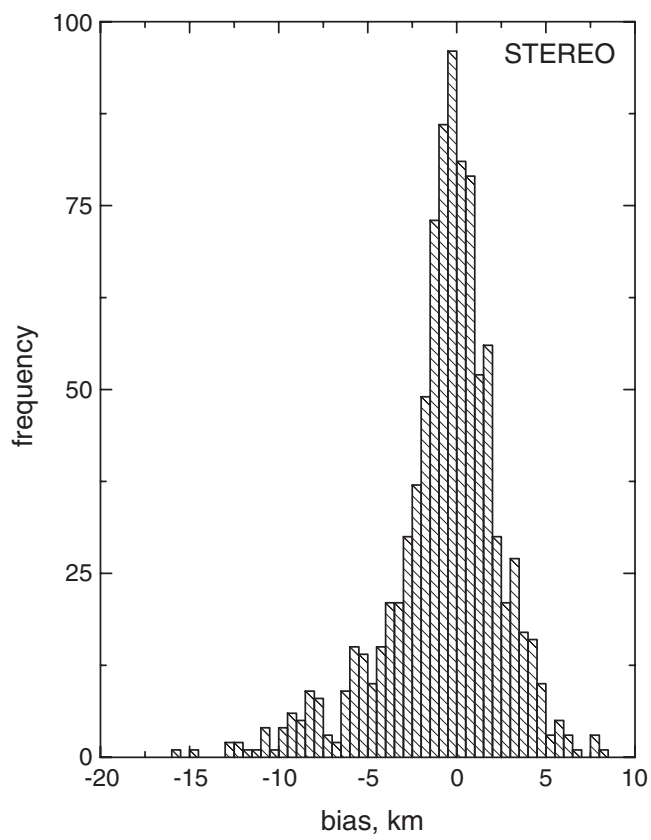

Fig. 6. Histogram of biases of stereoscopy-derived CTHs as compared to those derived using thermal IR measurements. Both measurements are performed by ATSR-2.

For comparison, we show in Table 1 also the performance of the cloud retrieval algorithm ROCINN (Loyola, 2004) used in the operational processing of GOME data. ROCINN delivers cloud top pressure and cloud top albedo using the measured $\mathrm{O}_{2}$ A-band reflectances and a known cloud fraction as derived by OCRA. $\mathrm{O}_{2}$ A-band top-of-atmosphere reflectances are simulated accounting for the attenuation due to the absorption of the direct solar beam by oxygen and its reflection from the ground or cloud top. Surfaces are assumed to be Lambertian reflectors. Considering only the transmittances along two photon paths through the atmosphere, the forward reflectivity model is computed as

$\rho(\lambda)=c_{f}\left\langle T_{c}\left(\lambda, \theta_{0}, \theta, \phi, c_{a}, c_{z}\right)\right\rangle+\left(1-c_{f}\right)\left\langle T_{s}\left(\lambda, \theta_{0}, \theta, \phi, s_{a}, s_{z}\right)\right\rangle$

where $\rho$ is the reflectivity factor (see Appendix A), $\lambda$ is the wavelength, $\theta_{0}$ is the solar zenith angle, $\theta$ is the satellite zenith angle, $\phi$ is the relative azimuth, $c_{a}$ is the cloud top albedo, $c_{z}$ is the cloud top altitude, $s_{a}$ is the ground surface albedo, $s_{z}$ is the underlying surface height. $\left\langle T_{c}\right\rangle$ denotes the convoluted transmittance from the sun to a satellite for a cloudy portion of the scene. $\left\langle T_{s}>\right.$ has the same meaning as $\left\langle T_{c}>\right.$ except for the clear portion of the ground scene. The calculations of the transmittance are used to create a complete data set of simulated reflectances for all GOME viewing geometries and geophysical scenarios, for various combinations of cloud fractions, cloud top heights, and cloud top albedos. ROCINN aims to retrieve cloud top height $c_{\mathrm{z}}$ and the cloud top albedo $c_{\mathrm{a}}$ using Eq. (1); the surface height $s_{\mathrm{Z}}$ and the ground albedo $s_{\mathrm{a}}$ are taken from a suitable database, and cloud fraction $c_{\mathrm{f}}$ is taken from the OCRA algorithm (see Appendix A). The inverse problem is solved using neural networks (Loyola, 2004).

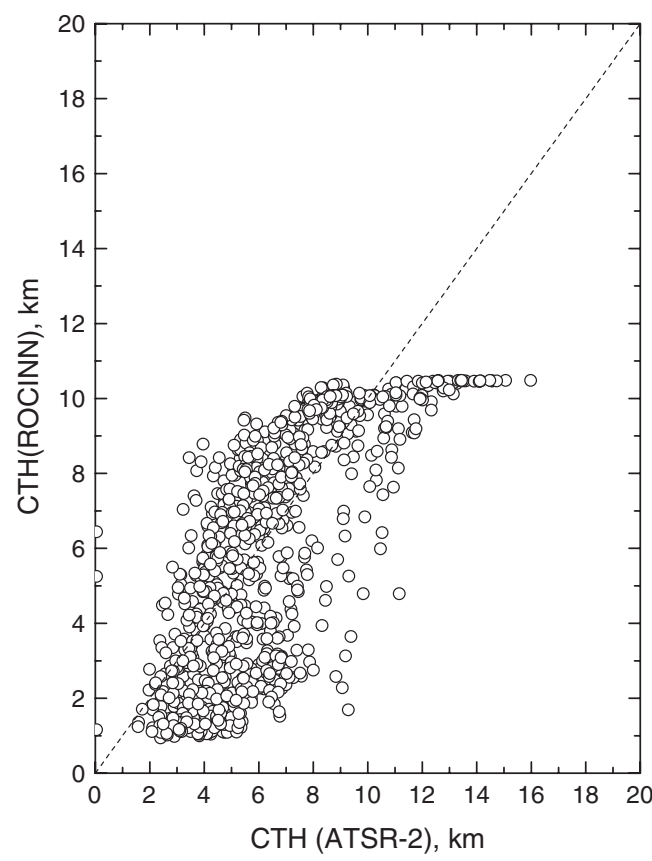

Fig. 7. The same as in Fig. 2 except for ROCINN.

It follows from data shown in Table 1 that ROCINN gives smaller average CTHs as compared to IR ATSR-2 and SACURA GOME retrievals. The average bias is $-0.5 \mathrm{~km}$ as compared to ATSR-2 retrievals. It is about $-1.1 \mathrm{~km}$ as compared to SACURA GOME retrievals. The standard deviation $\sigma$ of ROCINN is $2.2 \mathrm{~km}$ as compared to the value of $\sigma=1.8 \mathrm{~km}$ for SACURA-derived CTHs. The correlation with ATSR-2 data is not so pronounced as in the case of SACURA. This is shown in Figs. 7 and 8. It follows from Fig. 8 that ROCINN gives almost uniform distribution of

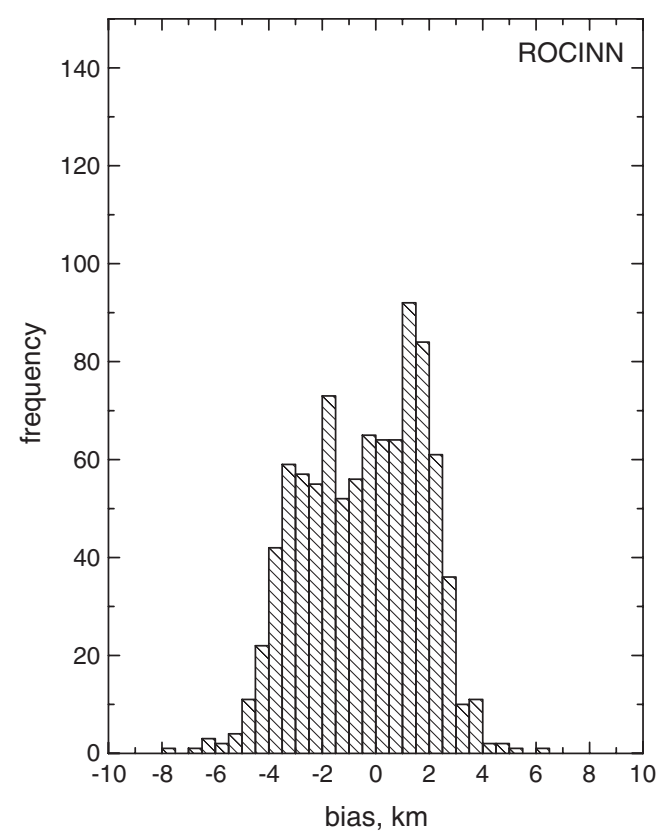

Fig. 8. Histogram of biases of ROCINN GOME-derived CTHs as compared to those derived using thermal IR measurements of ATSR-2. 
cloud top height biases in the range $[-2 \mathrm{~km}, 2 \mathrm{~km}]$ in contrast to a highly peaked distribution (at $B_{\mathrm{s}}=0$ ) as obtained using SACURA. This limitation is probably related to the fact that the operational ROCINN algorithm does not model multiple light scattering in a cloud (and also molecular and aerosol scattering). The maximum of CTH $(10.5 \mathrm{~km})$ as derived by ROCINN (see Fig. 7) is the retrieval constraint implemented in the algorithm. Namely, all clouds with heights above $10.5 \mathrm{~km}$ are assumed to have a height $10.5 \mathrm{~km}$. This limitation is planned to be dropped in the next version of ROCINN.

\section{Conclusions}

In summary, the average difference between $\mathrm{CTH}$ derived from GOME data using SACURA is $0.6 \pm 0.6 \mathrm{~km}$ as compared to thermal IR ATSR-2 retrievals. The standard deviation is equal to $1.8 \mathrm{~km}$. The average difference between CTHs derived from GOME data using ROCINN is $-0.5 \pm 1 \mathrm{~km}$ compared to ATSR2 retrievals, with a standard deviation of $2.2 \mathrm{~km}$. The ROCINN algorithm is currently being extended with a full multiple scattering treatment to overcome the limitations of using transmittances only.

SACURA and ROCINN GOME CTHs can be readily used to derive the cloud top altitudes needed for the total ozone concentration retrievals from information contained in GOME UV spectra, where a higher precision for the $\mathrm{CTH}$ product is not required because the ozone concentration maximum is located in the stratosphere well above clouds. Kokhanovsky et al. (in preparation) have shown that the error of derived total ozone concentration is below $1 \%$ for the bias of $1 \mathrm{~km}$ in $\mathrm{CTH}$ for completely cloudy pixels.

The SACURA algorithm can be further improved using cloud fractions as derived from ATSR-2 $\left(1.1 \pm 1.1 \mathrm{~km}^{2}\right)$ for GOME data. Another improvement is possible, if the value of reflectance for a clear sky is taken from satellite measurements of a minimal reflectance (e.g., at $758 \mathrm{~nm}$ ) and not from the model as it is done in the current version of SACURA.

The results of application of SACURA to all SCIAMACHY data for 4 years (2002-2005) of ENVISAT operation are given at www.iup.physik.uni-bremen.de. Cloud parameters retrieved with the OCRA and ROCINN algorithms for the complete GOME mission (starting in July 1995) can be found at http:// wdc.dlr.de/sensors/gome/gdp4.html. ATSR-2 retrievals of cloud top height, effective radius, and optical depth based on the GRAPE scheme are available from the BADC (www.badc. rl.ac.uk).

\section{Acknowledgements}

This work was partially supported by DFG Project BU 688/ 8-2 and also by German Ministry of Education and Research BMBF (grant 07UFE12/8) and the German Aerospace Center DLR (grant 50EE0027). The ATSR-2 cloud scheme was developed under work funded by the UK Natural Environment Research Council. This work is part of the EU Network of Excellence ACCENT.
The authors are grateful to C. Naud and also to two anonymous reviewers for many important comments on this paper.

\section{Appendix A. Optical cloud recognition algorithm}

The basic idea of the optical cloud recognition algorithm (OCRA) (Loyola \& Ruppert, 1998) is to separate optical sensor measurements into two components: a cloud-free background and a remainder influenced by clouds. The key to the algorithm is the construction of a cloud-free composite that is invariant with respect to the atmosphere, to topography, and to solar and viewing angles for a given point of observation. Initial preprocessing is required before multi-temporal data can be fused to develop the composite. For a given location $M(x, y)$ (e.g., a flat surface), the reflectance factor $\rho(x, y, \lambda)$ measured by the polarization measurement devices (PMDs) of GOME at the wavelength $\lambda$ for the ground cover projection of the image is defined as

$\rho(x, y, \lambda)=\frac{I(x, y, \lambda)}{F_{0}(\lambda) \cos \theta_{0}}$

where $I$ is the intensity of upwelling radiation, $F_{0}$ is the solar irradiance, and $\theta_{0}$ is the solar zenith angle. The PMDs measure backscattered light intensity not at a single wavelength but in rather broad spectral ranges: 295-397 nm (PMD1, blue), 347$580 \mathrm{~nm}$ (PMD2, green), and 580-745 nm (PMD3, red) (Burrows et al., 1999). This reflectance is translated into the normalized $r g$-color space via the relations:

$r=\frac{\rho\left(x, y, \lambda_{\mathrm{R}}\right)}{\sum_{i=\mathrm{R}, \mathrm{G}, \mathrm{B}} \rho\left(x, y, \lambda_{i}\right)}, g=\frac{\rho\left(x, y, \lambda_{\mathrm{G}}\right)}{\sum_{i=\mathrm{R}, \mathrm{G}, \mathrm{B}} \rho\left(x, y, \lambda_{i}\right)}$

where $B, G$, and $R$ denote measurements obtained by PMD1, PMD2, and PMD3, respectively. We underline that GOME PMDs have better spatial resolution $\left(20 \times 40 \mathrm{~km}^{2}\right)$ than GOME science pixels used in trace gas retrievals. This allow to detect the cloud structure of a large GOME pixel (typically, $320 \times 40 \mathrm{~km}^{2}$ ) using PMD measurements. Quantities $r$ and $g$ define a point in the $r g$ chromaticity diagram (Loyola \& Ruppert, 1998). By definition, the white point located at the position $W(1 / 3,1 / 3)$ in the $r-g$ space corresponds to a cloud. It is important to note that all clouds independently on their thickness are concentrated in the vicinity of the point $W$. The points correspondent to the minimal reflectance are located at positions $A_{j}$ in $r-g$ space. We found that measurements for partially cloudy positions for a given location $M(x, y)$ are concentrated on the line $\mathrm{WA}_{j}$ in the $r g$ space. It means that it is possible to conceive the cloud fraction algorithm based on the location of a given measurement point on the length $\ell=\left[W A_{j}\right]$. It follows that $\ell \rightarrow 0$ for spectrally neutral underlying surfaces (e.g., snow in the visible). Then, OCRA cannot be used. A detailed description of the algorithm is given by Loyola (2000).

Tuinder et al. (2004) compared several algorithms for retrieving cloud fraction using GOME against synoptic surface observations made by human eye. The OCRA algorithm 
outperforms the other cloud fraction algorithms used in that comparison. OCRA underestimates the cloud fraction compared to synoptic data, with a mean difference of $-10 \%$.

\section{References}

Bovensmann, H., et al. (1999). SCIAMACHY: Mission objectives and measurement modes. Journal of the Atmospheric Sciences, 56, 127-150.

Burrows, J. P., et al. (1999). The Global Ozone Monitoring Experiment (GOME): Mission concept and first scientific results. Journal of the Atmospheric Sciences, 56, 151-171.

Diner, D. J., Beckert, J. C., Reilly, T. H., Bruegge, C. J., Conel, J. E., Kahn, R. A., et al. (1998). Multi-angle Imaging SpectroRadiometer (MISR) instrument description and experiment overview. IEEE Transactions on Geoscience and Remote Sensing, 36, 1072-1087.

King, M. D., Kaufman, Y. J., Menzel, W. P., \& Tanre, D. (1992). Remote sensing of cloud, aerosol, and water vapor properties from the moderate resolution imaging spectrometer (MODIS). IEEE Transactions on Geoscience and Remote Sensing, 30, 2-27.

Kokhanovsky, A. A., et al. (2005). SCIAMACHY cloud products: Algorithms and examples from ENVISAT. Advances in Space Research, 36, 789-799.

Kokhanovsky, A. A. et al. (in preparation). The influence of clouds on the total ozone concentration retrievals from space for broken cloud conditions using backscattered solar light. International Journal of Remote Sensing.

Kokhanovsky, A. A., \& Rozanov, V. V. (2004). The physical parameterization of the top-of-atmosphere reflection function for a cloudy atmosphereunderlying surface system: The oxygen A-band case study. Journal of Quantitative Spectroscopy \& Radiative Transfer, 85, 35-55.

Kokhanovsky, A. A., \& Rozanov, V. V. (2005). Cloud bottom altitude determination from a satellite. IEEE Transactions on Geoscience and Remote Sensing, Letters, 2, 280-283.

Loyola, D. (2000). Cloud retrieval for SCIAMACHY. ERS-ENVISAT Symposium, Gothenburg.

Loyola, D. (2004). Automatic cloud analysis from polar-orbiting satellites using neural network and data fusion techniques. IEEE International Geoscience and Remote Sensing Symposium, 4, 2530-2534.

Loyola, D., \& Ruppert, T. (1998). A new PMD cloud-recognition algorithm for GOME. ESA Earth Observation Quarterly, 58, 45-47.

Menzel, W. P., Baum, B. A., Strabala, K. I., \& Frey, R. A. (2002). Cloud top properties and cloud phase algorithm theoretical basis document. Algorithm theoretical basis document, ATBD_MOD_04, NASA GSFC (http:// modis-atmos.gsfc.nasa.gov/_docs/atbd_mod04.pdf).
Moroney, C., Davies, R., \& Muller, J. -P. (2002). Operational retrieval of cloudtop heights using MISR data. IEEE Transactions on Geoscience and Remote Sensing, 40, 1532-1546.

Naud, C., Michell, K. L., Muller, J.- P., Clothiaux, E. E., Albert, P., Preusker, R., Fischer, J., \& Hogan, R. J. (in press). Comparison between ATSR2 stereo, MOS O2-A band and ground-based cloud top heights. International Journal of Remote Sensing.

Naud, C., Muller, J. -P., \& de Valk, P. (2005a). On the use of ICESAT-GLAS measurements for MODIS and SEVIRI cloud-top height accuracy assessment. Geophysical Research Letters, 32, L19815, doi:10.1029/ 2005 GL023275.

Naud, C. M., Muller, J. -P., Clothiaux, E. E., Baum, B. A., \& Menzel, W. P. (2005b). Intercomparison of multiple years of MODIS, MISR and radar cloud-top heights. Annales Geophysicae, 23, 2415-2424.

Naud, C., Muller, P., \& Clothiaux, E. C. (2002). Comparison of cloud top heights derived from MISR stereo and MODIS $\mathrm{CO}_{2}$ slicing. Geophysical Research Letters, 29, doi:10.1029/2002GL015460.

Rozanov, V. V., \& Kokhanovsky, A. A. (2004). Semi-analytical cloud retrieval algorithm as applied to the cloud top altitude and the cloud geometrical thickness determination from top of atmosphere reflectance measurements in the oxygen absorption bands. Journal of Geophysical Research, 109, D05202, doi:10.1029/2003JD004104.

Rozanov, V. V., Kokhanovsky, A. A., \& Burrows, J. P. (2004). The determination of cloud altitudes using GOME reflectance spectra: Multilayered cloud systems. IEEE Transactions on Geoscience and Remote Sensing, 42, 1009-1017.

Sherwood, S. C., Chae, J. -H., Minnis, P., \& McGill, M. (2004). Underestimation of deep convective cloud tops by thermal imagery. Geophysical Research Letters, 31, L11102, doi:10.1029/2004GL019699.

Siddans, R., Kerridge, B., Reburn, W. J., Stevens, A., \& Munro, R. (1999). Height-resolved ozone retrievals spanning the troposphere and stratosphere from GOME. ESAMS '99-European symposium on atmospheric measurements from space (pp. 299-305). Noordwijk: ESA.

Spurr, R., Loyola, D., Thomas, W., Balzer, W., Mikusch, E., Aberle, B., et al. (2005). GOME level 1-to-2 data processor version 3.0: A major upgrade of the GOME/ERS-2 total ozone retrieval algorithm. Applied Optics, 44(33), 7196-7207.

Stricker, N. C. M., Hahne, A., Smith, D. L., Delderfield, J., Oliver, M. B., \& Edwards, T. (1995, August). ATSR-2: The evolution in its design from ERS1 to ERS-2. ESA Bulletin, 83.

Tuinder, O. N. E., de Winter-Sorkina, R., \& Builtjes, P. J. H. (2004). Retrieval methods of effective cloud cover for the GOME instrument: An intercomparison. Atmospheric Chemistry and Physics, 4, 255-273. 